\title{
Sublingual versus subcutaneous immunotherapy: patient adherence at a large German allergy center
}

\author{
Marie-Luise Lemberg' \\ Till Berk ${ }^{2}$ \\ Kija Shah-Hosseini' \\ Elena-Manja Kasche ${ }^{1,3}$ \\ Ralph Mösges'
}

'Faculty of Medicine, Institute of Medical Statistics, Informatics and Epidemiology, University of Cologne, Cologne, Germany; ${ }^{2}$ Department of Trauma Surgery, University Hospital Zurich, Zurich, Switzerland; ${ }^{3}$ Center for Dermatology, Specific Allergology and Environmental Medicine,

Hamburg, Germany
Correspondence: Ralph Mösges Faculty of Medicine, Institute of Medical Statistics, Informatics and Epidemiology, University of Cologne, Lindenburger Allee 42, Cologne 5093I, Germany

Tel +4922147882929

Fax +49221 47882940

Email ralph@moesges.de
This article was published in the following Dove Press journal:

Patient Preference and Adherence

4 January 2017

Number of times this article has been viewed

Background: Many placebo-controlled studies have demonstrated that allergen immunotherapy (AIT) is an effective therapy for treating allergies. Both commonly used routes, subcutaneous (SCIT) and sublingual immunotherapy (SLIT), require high patient adherence to be successful. In the literature, numbers describing adherence vary widely; this investigation compares these two routes of therapy directly.

Methods: All data were retrieved from the patient data management system of a center for dermatology, specific allergology, and environmental medicine in Germany. All 330 patients (aged 13-89 years) included in this study had commenced AIT between 2003 and 2011, thus allowing a full 3-year AIT cycle to be considered for each investigated patient.

Results: In this specific center, SCIT was prescribed to $62.7 \%$ and SLIT to $37.3 \%$ of all included patients. The total dropout rate of the whole patient cohort was $34.8 \%$. Overall, SLIT patients showed a higher dropout rate (39.0\%) than did SCIT patients (32.4\%); however, the difference between these groups was not significant. Also, no significant difference between the overall dropout rates for men and for women was observed. A Kaplan-Meier curve of the patient collective showed a remarkably high dropout rate for the first year of therapy.

Conclusion: The analysis presented in this single-center study shows that most patients who discontinue AIT do so during the first year of therapy. Patients seem likely to finish the 3-year therapy cycle if they manage to adhere to treatment throughout the first year. Strategies for preventing nonadherence in AIT, therefore, need to be developed and standardized in future investigations. Keywords: adherence, dropout, nonadherence, SCIT, SLIT, allergic rhinitis, allergy, allergen immunotherapy

\section{Introduction}

For more than a century, allergen immunotherapy (AIT) has been the only diseasemodifying therapy to treat allergies. AIT targets freedom from symptoms and can be administered through subcutaneous (SCIT) or sublingual immunotherapy (SLIT) routes. ${ }^{1,2}$ Major studies have proven the efficiency of AIT, ${ }^{3}$ although this treatment modality requires patients to be adherent for at least 3 years ${ }^{4}$ for it to succeed. This requirement outlines the main challenge: patients are rarely adherent to long-term therapy of chronic diseases. ${ }^{5}$ Adherence to the available forms of AIT-SCIT and SLIT-appears to be no exception. In the literature, figures on adherence to SCIT and to SLIT differ immensely. SLIT adherence rates are reported to be between 7\% and $82 \%$, whereas SCIT adherence rates range from $23 \%$ to $55 \% .^{5-8}$ Reasons for nonadherence vary with the most commonly cited reasons for nonadherence to SLIT being nonperception of efficacy, costs, and side effects. ${ }^{9-11}$ 
Four dimensions of causes for nonadherence are usually mentioned: patient-centered factors, health care delivery factors, disease-related factors, and treatment-related factors. ${ }^{12}$ The complexity and variety of factors influencing adherence to AIT are extensive. ${ }^{13}$

SCIT has been available in Germany for decades, whereas the first SLIT drops were registered in Germany in 2004 and the first SLIT grass tablet in $2006 .{ }^{14}$ To gain a broader picture of the adherence to these two common routes of therapy, we decided to analyze the differences between adherence to SCIT and adherence to SLIT in patients at one private allergy center in Germany. By analyzing patient adherence in only one physician's practice retrospectively, we were able to avoid bias resulting from different health care delivery procedures and to obtain data that were immediately comparable.

\section{Materials and methods Population}

Data were retrieved from one German private allergy center providing care to patients who have statutory or private health insurance. Therefore, all health care expenses and medication costs were reimbursed $100 \%$. Data of patients who had started AIT in 2003 or later had been saved in the center's practice management system (MediSoftware, Kiel, Germany). The patient information was evaluated anonymously and retrospectively.

This study included patients who had begun AIT between 2003 and 2011, allowing a full 3-year cycle to be pictured for each patient. In all, 330 patients aged 13-89 years were involved in this analysis. Besides demographical data, the patients' former and current diagnoses, medication as well as forms and duration of therapy were also documented. Furthermore, the personal allergy history and the allergen spectrum, that is, whether the patients were monosensitized or polysensitized, were also assessed.

\section{The practice}

Data were obtained in a private practice with two locations, both in Hamburg, Germany. The participating physicians were specialized in dermatology with a subspecialization in allergology. This specialization involves 2-year training, board certification, and further continuing medical education. In all, 1,825 patients were diagnosed with allergic rhinitis between 2003 and 2011,330 (18.1\%) of whom were eligible for immunotherapy according to the German guidelines.

\section{Immunotherapy}

In total, 83 different allergen extracts from 9 manufacturers were prescribed to the patients. The allergen extracts most often prescribed were for allergy to the pollen of grass, birch tree, alder tree, hazel tree, wheat, and rye, as well as for allergy to house dust mites and wasps. For a detailed summary of the SCIT and SLIT compounds used (Table 1).

SCIT compounds were based either on native, nonmodified extracts that used unchanged conformation of allergens, or on polymerized allergoids. Semidepot allergen extracts were applied most often, which contain native or modified allergens that are based on calcium phosphate, tyrosine, or aluminum hydroxide.

SLIT compounds were prescribed as drops or tablets containing allergoids or native allergens. According to the manufacturer, some of the tablets or drops required storage in a refrigerator or at room temperature.

Following the German guidelines for AIT, SCIT patients were required to stay at the practice for at least 30 minutes after each injection so that any possible anaphylactic reactions could be treated immediately. SLIT patients received their first tablet or drops under observation and had to remain in the practice for 30 minutes. Thereafter, SLIT treatment was self-administered by the patients; the patients were able to renew their prescription by phone and continue their treatment at home. ${ }^{15}$

\section{Mode of therapy}

The different modes of therapy were prescribed taking into consideration the patient's preferred route of therapy, the allergy itself, the manufacturer's recommendations, the patient's allergy history, and the patient's personal circumstances.

Preseasonal modes were usually administered for seasonal allergies, and allergens were only given for 4 months before each season. The dosage of allergens was increased to a maximum in a short amount of time just before the season and was discontinued for the duration of the season and the time immediately after (8 months). A complete treatment cycle (including interruptions) lasted at least 28 consecutive months (Figure 1).

Pre-coseasonal modes started before each season and continued throughout the season but paused after the season. Treatment began again shortly before the next season. A complete treatment cycle (including pauses) comprised at least 28 consecutive months.

Perennial modes usually involved one injection every 4-6 weeks, totaling 8-12 injections per year, over a period of at least 36 months with the same constant dosage of allergens.

Perennial-seasonal mode means that the patients were polysensitized; different allergens were given according to their needed scheme, perennially and seasonally. This mode also consisted of at least 36 consecutive months of therapy. 
Table I Allergen extracts used in the SCIT and SLIT patients studied

\begin{tabular}{|c|c|c|c|c|c|}
\hline Manufacturer & Product & Allergens & $\begin{array}{l}\text { Route of } \\
\text { therapy }\end{array}$ & Mode of therapy (n) & No of patients \\
\hline Allergopharma & Acaroid & House dust mite & SCIT & Perennial (2) & 2 \\
\hline ALK & ALK-7 & $\begin{array}{l}\text { Early flowering trees mix (alder, hazel, birch } \\
\text { tree), wasp, grass pollen, house dust mite, birch } \\
\text { tree, ryegrass }\end{array}$ & SCIT & $\begin{array}{l}\text { Perennial-seasonal (2), } \\
\text { perennial (II), preseasonal ( } 8) \text {, } \\
\text { short-term (I) }\end{array}$ & 22 \\
\hline Allergopharma & Allergovit & $\begin{array}{l}\text { Grass pollen, grass pollen and grains mix, tree } \\
\text { (alder, hazel, birch tree) and mugwort mix, early } \\
\text { flowering trees (birch, alder, hazel tree), grass } \\
\text { and rye pollen mix }\end{array}$ & SCIT & $\begin{array}{l}\text { Perennial (3), perennial-seasonal } \\
\text { (8), preseasonal }(2 I)\end{array}$ & 32 \\
\hline ALK & Avanz & $\begin{array}{l}\text { Early flowering trees mix (alder, hazel, birch } \\
\text { tree), grass and rye pollen mix }\end{array}$ & SCIT & Preseasonal (2) & 2 \\
\hline Roxall Medizin & Clustoid & $\begin{array}{l}\text { Early flowering trees mix (alder, hazel, birch } \\
\text { tree), grass pollen, grass and rye pollen mix }\end{array}$ & SCIT & $\begin{array}{l}\text { Perennial (2), perennial-seasonal } \\
\text { (24), preseasonal ( } 9 \text { ) }\end{array}$ & 35 \\
\hline $\begin{array}{l}\text { Novartis } \\
\text { Pharma }\end{array}$ & Depigoid & $\begin{array}{l}\text { House dust mite, grass pollen, ryegrass, tree mix, } \\
\text { early flowering trees mix (alder, hazel, birch tree) }\end{array}$ & SCIT & $\begin{array}{l}\text { Perennial (10), perennial- } \\
\text { seasonal (16), preseasonal (9) }\end{array}$ & 35 \\
\hline Allergopharma & Novohelisen & $\begin{array}{l}\text { House dust mite, cotton, grass pollen, birch } \\
\text { tree and ryegrass mix }\end{array}$ & SCIT & $\begin{array}{l}\text { Perennial }(\mathrm{I}) \text {, perennial-seasonal } \\
(\mathrm{I}) \text {, preseasonal }(\mathrm{I})\end{array}$ & 3 \\
\hline \multicolumn{6}{|l|}{ Allergie } \\
\hline HAL Allergie & Purethal & $\begin{array}{l}\text { Grass pollen, tree mix, birch tree, house } \\
\text { dust mite }\end{array}$ & SCIT & $\begin{array}{l}\text { Perennial }(\mathrm{I}) \text {, perennial-seasonal } \\
(\mathrm{I}) \text {, preseasonal }(\mathrm{I}) \text {, short-term (I) }\end{array}$ & 4 \\
\hline Roxall & Roxoid & $\begin{array}{l}\text { Early flowering trees mix (alder, hazel, birch tree), } \\
\text { grasses, tree mix, ryegrass, house dust mite }\end{array}$ & SCIT & $\begin{array}{l}\text { Perennial (4), perennial-seasonal } \\
\text { (I5), preseasonal (II) }\end{array}$ & 30 \\
\hline \multirow[t]{2}{*}{ ALK } & Scherax & $\begin{array}{l}\text { Early flowering trees mix (alder, hazel, birch tree), } \\
\text { grass pollen, ryegrass, wasp, house dust mite }\end{array}$ & SCIT & $\begin{array}{l}\text { Preseasonal (II), perennial }(\mathrm{I} 2) \text {, } \\
\text { perennial-seasonal (I8) }\end{array}$ & 41 \\
\hline & & & SCIT & & Total number $=207$ \\
\hline Pharma Gerke & Grazax Lyo & Grass pollen & SLIT & Preseasonal (5), pre-coseasonal (I) & 6 \\
\hline Lofarma & Lais & Tree mix (birch and alder), house dust mite, cat & SLIT & $\begin{array}{l}\text { Perennial (16), preseasonal (I7), } \\
\text { pre-coseasonal (I) }\end{array}$ & 34 \\
\hline Stallergénes & Oralair & Grass and rye pollen mix & SLIT & $\begin{array}{l}\text { Perennial-seasonal (I), preseasonal } \\
\text { (14), pre-coseasonal (25) }\end{array}$ & 40 \\
\hline \multirow[t]{2}{*}{ Stallergénes } & Staloral & $\begin{array}{l}\text { Early flowering trees mix (alder, hazel, birch tree), } \\
\text { grass pollen, tree mix, ryegrass, house dust mite }\end{array}$ & SLIT & $\begin{array}{l}\text { Perennial (9), perennial- } \\
\text { seasonal (I), preseasonal (28), } \\
\text { pre-coseasonal (5) }\end{array}$ & 43 \\
\hline & & & SLIT & & Total number $=123$ \\
\hline
\end{tabular}

Abbreviations: SCIT, subcutaneous immunotherapy; SLIT, sublingual immunotherapy.

Short-term immunotherapy comprised 4-8 injections before the season and also required a consecutive 36-month cycle.

\section{Adherence data}

Adherence was measured retrospectively and indirectly by analyzing patient data with respect to the starting date of therapy and the termination date. The perennial and the perennial-seasonal modes of therapy and the short-term immunotherapy were scheduled to consist of 36 months of

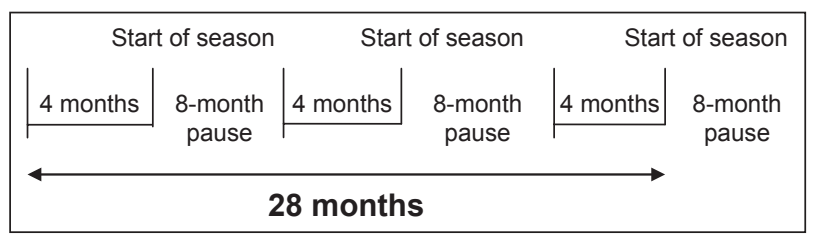

Figure I Preseasonal mode of immunotherapy. treatment in total. The preseasonal and pre-coseasonal modes of therapy were scheduled to comprise at least 28 months of treatment (Figure 1). Any patient who abandoned therapy before that set amount of time was considered a dropout.

\section{Data management}

Statistics were compiled and analyzed using IBM SPSS Statistics for Windows (version 22.0, IBM Corp., Armonk, NY, USA) and Microsoft Excel (Microsoft Corporation, Redmond, Washington, DC, USA). Quantitative parameters were expressed as means and in percentages with respect to the entire population. Any statistical conspicuity was validated with a Mann-Whitney $U$ test or Fisher's exact test to determine statistical significance, which was defined as $P<0.05$.

All patients had formerly consented to the treatment. A written informed consent for the study was not necessary 
because it was a retrospective anonymous analysis. Retrospect use of data by the treating physician for scientific purposes is allowed and desired. We did, however, consult the official ethics committee of the University of Cologne, which confirmed that the data came from the coauthor Kasche and may be used anonymously by her and our research institute. According to German law, there is no need for a consultation of the ethics committee.

\section{Results}

\section{Patients' demographic characteristics}

The observed population of 330 patients consisted of 207 SCIT and 123 SLIT patients. Table 2 shows the demographic and therapy-related characteristics of the population studied. An analysis of the patient data revealed a significant difference in age between SCIT and SLIT patients in the whole collective $(P=0.01)$. SLIT patients were younger than SCIT patients. All other demographic characteristics showed no significant differences (Table 2).

\section{Dropouts}

In total, 115 (34.8\%) patients dropped out of AIT before completing their respective 3-year therapy cycle. The patients who terminated therapy prematurely were significantly younger than the entire group of patients evaluated $(P<0.001)$. The average age of nonadherent patients was 38.6 years, whereas adherent patients had an average age of 44.5 years. The analysis of dropouts by sex and age showed no significant differences. The difference between men and women who terminated therapy prematurely was not statistically significant. Similarly, the difference between male and female dropouts within the SLIT or SCIT groups was not significant. The dropout numbers according to allergen extract are pictured in Table 3 .

\section{Survival rate}

A Kaplan-Meier survival curve resulted in similar trends for both routes of therapy. Figure 2 shows that most patients who dropped out did so during the first year of therapy. Those patients who continued with the second year of therapy were more likely to accomplish the full 3 years of treatment. SCIT patients in this practice generally tended to be more adherent to their therapy than SLIT patients were to theirs.

\section{Patients' reasons for dropping out}

The data on patients' motives for dropping out of therapy were based on the physician-patient consultation and the corresponding physician's records that were entered into the data management system. Only 32 (27.8\%) of the 115 patients who dropped out were willing to state their reasons for doing so in a physician-patient conversation. The following reasons were documented: 10 patients (31\%) stated move or travel, 7 (22\%) noncompliance, 6 patients (19\%) reported adverse effects, 4 patients (13\%) stated pregnancy or the desire to have a child, $3(9 \%)$ blamed long waiting hours at the practice, and 2 patients (6\%) changed the route of therapy from SCIT to SLIT.

Table 2 Demographic and therapy-related characteristics of the SLIT and SCIT patients studied

\begin{tabular}{|c|c|c|c|}
\hline & SCIT & SLIT & Total \\
\hline All patients, n (\%) & $207(62.7)$ & $123(37.3)$ & 330 \\
\hline Female patients, n (\%) & $f=106(51.2)$ & $f=70(56.9)$ & $f=176(53.3), P=0.315 \mathrm{NS}$ \\
\hline Mean age in years (range: & $43.72 \pm 15.11$ & $40.36 \pm 16.39$ & $42.46 \pm 15.63, \mathrm{~m}=40.0 \pm \mid 4.28$ \\
\hline 13-89 years) & & & $f=44.6 I \pm 16.43, P=0.01$ \\
\hline \multicolumn{4}{|l|}{ Mode of therapy } \\
\hline Preseasonal, n (\%) & $74(22.4)$ & $66(20.0)$ & 140 (42.4) \\
\hline Pre-coseasonal, n (\%) & 0 & $32(9.7)$ & $32(9.7)$ \\
\hline Perennial, n (\%) & $45(13.6)$ & $25(7.6)$ & $70(2 I .2)$ \\
\hline Perennial-seasonal, n (\%) & $86(26.1)$ & 0 & $86(26.1)$ \\
\hline Short-term immunotherapy, n (\%) & $2(0.6)$ & 0 & $2(0.6)$ \\
\hline \multicolumn{4}{|l|}{ Dropout } \\
\hline All patients, n (\%) & $67(32.4)$ & $48(39.0)$ & II 5 (34.8), $P=0.220$ NS \\
\hline Female patients, n (\%) & $f=34(32.1), P=0.927 \mathrm{NS}$ & $f=32(45.7), P=0.08 \mathrm{NS}$ & $f=66(37.5), P=0.28 \mathrm{NS}$ \\
\hline Mean age in years & $39.9 \pm 15.62$ & $36.7 \pm 14.49$ & $38.6 \pm 15.02$ \\
\hline \multicolumn{4}{|l|}{ Modes of therapy of dropout patients } \\
\hline Preseasonal, n (\%) & 31 (4I.9) & $25(37.9)$ & $56(40.0)$ \\
\hline Pre-coseasonal, n (\%) & 0 & $14(43.8)$ & $14(43.8)$ \\
\hline Perennial, n (\%) & $9(20.0)$ & $9(36.0)$ & $18(25.7)$ \\
\hline Perennial-seasonal, n (\%) & $26(30.2)$ & 0 & $26(30.2)$ \\
\hline Short-term immunotherapy, n (\%) & I (50.0) & 0 & I (50.0) \\
\hline
\end{tabular}

Abbreviations: NS, not significant; SCIT, subcutaneous immunotherapy; SLIT, sublingual immunotherapy. 
Table 3 Dropouts by allergen extract

\begin{tabular}{ll}
\hline Allergen extract & $\begin{array}{l}\text { No of } \\
\text { dropouts }\end{array}$ \\
\hline Allergovit & 16 \\
Depigoid & 15 \\
Lais & 15 \\
Staloral & 14 \\
Clustoid & 13 \\
Oralair & 13 \\
Roxoid & 11 \\
ALK - depot & 7 \\
Grazax & 6 \\
Scherax & 4 \\
Novohelisen & 1
\end{tabular}

\section{Reported adverse reactions}

A retrospective analysis showed that $1.8 \%$ of the population (6 of 330) experienced an anaphylactic reaction. All 6 cases of anaphylaxis occurred in patients treated with SCIT. Two patients were treated with Clustoid ${ }^{\circledR}$ grass pollen SCIT, 1 with ALK-Scherax mite mix, 1 with ALK-Scherax early flowering tree mix, 1 with Allergovit ${ }^{\circledR}$ birch/alder/hazel mix, and 1 with ALK wasp. All of the adverse events were grade 1 or 2 reactions retrospectively rated according to the World Allergy Organization SCIT Systemic Reaction Grading system. ${ }^{16}$ No case required an epinephrine injection.

In all, 58 patients $(\mathrm{m}=24, f=34)$ reported negative side effects (ie, mild swelling, redness, and temporary dizziness); 48 of these patients $(23.2 \%)$ were treated with SCIT.

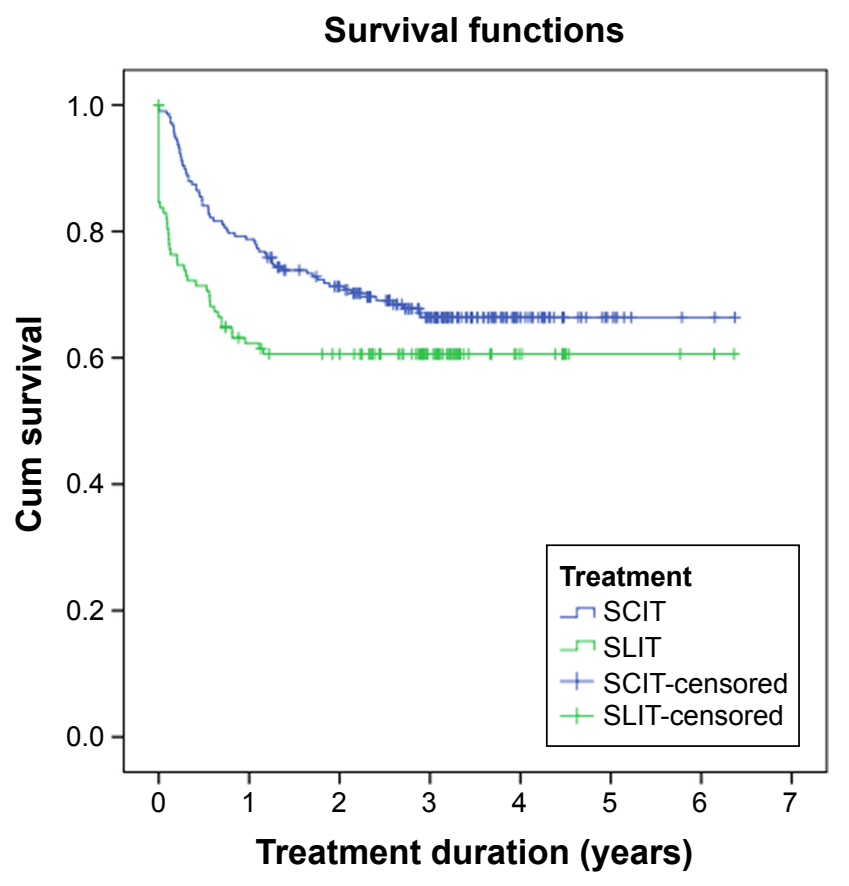

Figure 2 Kaplan-Meier curve of SCIT and SLIT patients illustrating dropout from therapy over time.

Abbreviations: SCIT, subcutaneous immunotherapy; SLIT, sublingual immunotherapy.

\section{Discussion} The range of adherence to SLIT and SCIT in the literature

Our results suggest that adherence to SLIT is not as good as adherence to SCIT; however, a significant difference could not be verified. To evaluate our outcome, we searched the literature for similar observations. Four other studies have previously analyzed adherence to AIT with respect to a full 3-year therapy cycle. All of these studies were retrospective and aimed to compare the two AIT routes: SCIT and SLIT. ${ }^{6-8,17}$ The dropout rate for SLIT patients ranged from $41 \%$ to $93 \%$ versus $40 \%$ to $77 \%$ for SCIT patients.

Table 4 provides an overview of studies comparing SLIT and SCIT adherence with respect to the studies' definitions of dropouts, sources of data, sample sizes, and dropout rates.

The retrospective study from the Netherlands shows a high number of dropouts during the first year of therapy; in the second and third years, those numbers increased slowly and gradually. The observations of the time-dependent course of dropouts correlate with ours. The overall compliance rate for completing AIT was $18 \%$. The compliance rate of $23 \%$ in SCIT patients was better than that in SLIT patients (7\%). The median duration of therapy was 1.7 years in SCIT patients and 0.6 years in SLIT patients. ${ }^{7}$ The Netherlands' health care system is different than Germany's, which may generally prevent the comparability of study results from these countries. In the Netherlands, often the patient's first contact with immunotherapy is through a specialist, but due to scarcity of specialists, most patients are referred back to their general practitioner. That circumstance may influence and explain the high dropout rate in the first year. In conclusion, especially regarding the health care delivery factors to adherence, the data from this particular Dutch study have to be interpreted carefully.

A recent German study that examined the sales data from one manufacturer for 5 consecutive years confirms our results, indicating that adherence to SCIT is better than adherence to SLIT. SLIT patients showed a particularly poor adherence rate of $16 \%$ in total. It is worth particular mention that the investigated population of 85,241 SCIT patients and 706 SLIT patients was very large. Children and adolescents were found to be more compliant than adults. ${ }^{8}$ Because the data were provided by only one manufacturer, the results from that study are hardly comparable to those from other studies.

Our retrospective analysis, however, did in fact uncover a significant difference between the age groups of patients 
Table 4 Overview of studies comparing SLIT and SCIT adherence

\begin{tabular}{|c|c|c|c|c|c|}
\hline Study & Definition dropout & Data source & $\begin{array}{l}\text { Study } \\
\text { sample size }\end{array}$ & $\begin{array}{l}\text { Dropout rate } \\
\text { SLIT (\%) }\end{array}$ & $\begin{array}{l}\text { Dropout rate } \\
\text { SCIT (\%) }\end{array}$ \\
\hline Sieber et $\mathrm{al}^{6}$ & $\begin{array}{l}\text { No prescription renewal in } \\
\text { the second year of therapy }\end{array}$ & $\begin{array}{l}\text { National prescription data base, } \\
\text { Germany }\end{array}$ & $\begin{array}{l}\text { I,410 children, } \\
\text { adolescents, adults }\end{array}$ & 49 & 64 \\
\hline Hsu and Reisacher ${ }^{17}$ & $\begin{array}{l}\text { 3-year therapy cycle was } \\
\text { not accomplished }\end{array}$ & $\begin{array}{l}\text { Patient data from a department at } \\
\text { a medical college, US }\end{array}$ & $\begin{array}{l}78 \text { children, } \\
\text { adolescents, adults }\end{array}$ & 41 & 45 \\
\hline Kiel et $\mathrm{al}^{7}$ & $\begin{array}{l}\text { 3-year therapy cycle was } \\
\text { not accomplished }\end{array}$ & $\begin{array}{l}\text { Community pharmacy database, } \\
\text { the Netherlands }\end{array}$ & 6,486 adults & 93 & 77 \\
\hline Egert-Schmidt et $\mathrm{al}^{8}$ & $\begin{array}{l}\text { 3-year therapy cycle was } \\
\text { not accomplished }\end{array}$ & $\begin{array}{l}\text { One manufacturer's sales data, } \\
\text { Germany }\end{array}$ & $\begin{array}{l}85,947 \text { children, } \\
\text { adolescents, adults }\end{array}$ & 84 & $40-73$ \\
\hline Our study & $\begin{array}{l}\text { 3-year therapy cycle was } \\
\text { not accomplished }\end{array}$ & $\begin{array}{l}\text { Patient data from one } \\
\text { dermatologist's practice, Germany }\end{array}$ & $\begin{array}{l}330 \text { adolescents, } \\
\text { adults }\end{array}$ & 39 & 32 \\
\hline
\end{tabular}

Abbreviations: SCIT, subcutaneous immunotherapy; SLIT, sublingual immunotherapy.

who dropped out of therapy. Also, our analysis showed that the reasons stated for dropping out were mainly patientrelated and not due to a lack of communication or information. A study published in 2012 also aimed to determine the reasons why patients discontinue AIT. The motives for discontinuing AIT differed between the treatment groups: SCIT patients most often stated inconvenience as the reason, whereas SLIT patients doubted the efficacy of this treatment. Overall, $45 \%$ of SCIT patients and $41 \%$ of SLIT patients did not fulfill the treatment requirement of 3 years, resulting in no significant difference in adherence. Concerning the duration of therapy, too, no significant difference between the groups could be recognized. ${ }^{17}$ The health care setting in this study was similar to that of our study; likewise, the results of dropout rates were also similar.

One aspect of our results concurs with one of the observations Sieber et al made when they examined the medication persistence for AIT in 1,409 patients. Our common observations showed that younger patients tended to drop out of therapy before completing the 3-year treatment cycle. The study by Sieber et al evaluated prescription renewal and followed SCIT and SLIT patients for 3 consecutive years. The patients were grouped according to whether they had received natural extract SLIT, natural extract SCIT, or allergoid SCIT. There was no significant difference in adherence between the two SCIT groups (dropout rate of $66 \%$ in the SCIT extract group and $62 \%$ in the SCIT allergoid group); however, the SLIT patients were more adherent to treatment, having a lower dropout rate of $49 \%$. Female patients and middle-aged patients were more likely to terminate treatment prematurely. ${ }^{6}$

Leader et al have just published a retrospective review comparing the compliance to SLIT and to SCIT at one setting. They observed a significantly better compliance to SCIT $(85 \%)$ than to SLIT $(66 \%)$. One must consider that their results were obtained using a specific definition of compliance based on a rating scale of compliance from poor, fair, good to excellent. That circumstance makes it rather difficult to compare their results to those of the studies depicted in Table $4 .{ }^{18}$

Due to different data sources, allergen extracts, populations, and different health care systems, an immediate comparison between our results and the aforementioned studies that targeted the same study goal is not reliable. It should be pointed out, however, that results obtained when comparing adherence continue to diverge widely.

SLIT and SCIT compounds are also not comparable due to their distinct and individual compositions. Moreover, the different methods used by manufacturers to measure the concentration of allergens preclude a comparison of the compounds at all..$^{15}$

\section{Reasoning nonadherence to AIT}

The study presented here offers clear evidence that the first year of therapy is a crucial turning point for patient adherence. It appears that once patients manage to be adherent in the first year, they are more likely to complete the rest of their respective AIT.

Only few patients were willing to explain to the physician why they had stopped therapy. Overall, $66 \%$ of the reasons for terminating therapy prematurely were based on patient-related factors. For example, $31 \%$ of dropouts did not finish their therapy because they had moved away from that practice. However, we cannot actually be sure that they did not continue therapy at another practice. Nonadherence was the cause of therapy discontinuation for $22 \%$ of dropouts. Also, $13 \%$ of dropouts who terminated therapy were women wishing to become pregnant. One must also consider this study's setting in the German health care system, in which patients receive $100 \%$ reimbursement for allergy 
treatment expenses. This situation completely excludes costs as a factor influencing adherence.

So far, no studies have proposed an explanation as to why patients adhere more poorly to SLIT than to SCIT. One starting point for an explanation, however, could be the lack of standardized SLIT dosages. Pfaar et $\mathrm{al}^{19}$ have just reported in a dose-finding study that the most efficient SLIT dose has not yet been established for birch tree pollen. They found that the higher the dosage of birch allergens, the better the symptom scores and improvement. The differences were statistically significant. This study outcome raises questions about the efficacy of SLIT itself. ${ }^{19}$ Hence, nonperception of efficacy is strongly supported as a reason for nonadherence with this outcome. The lack of SLIT dosage recommendations has also been outlined by Leatherman et $\mathrm{al}^{20}$ and its meaning cannot be neglected in reasoning nonadherence.

To improve patients' long-term adherence, all dimensions of management strategies need to be taken into consideration and enhanced. The health care team in particular can strive toward agreement with the patient on a treatment strategy that puts the patient's needs first. Fostering a solid, supportive physician-patient relationship may thus prevent patient-related factors for nonadherence. Antico stated that patient-related factors for nonadherence can be prevented with interventions in the physician-patient relationship. The first intervention he describes is to explain the allergy itself to the patient and then to explain the therapy itself to improve the patient's knowledge and awareness. ${ }^{13}$ A few studies have already identified the importance of suitable patient information. Interestingly, a German study emphasized that even when patients said they felt well informed, less than half of them could answer 5 questions about their therapy correctly. ${ }^{21}$ The importance of being well-informed and its consequences for adherence were clearly demonstrated in a recent study that conducted an online patient survey in five countries (USA, France, Spain, Germany, and Russia) with 261 patients who had been treated with AIT. The outcome was alarming: $28 \%$ of all patients did not know which allergen was being administered to them during AIT. Another $27 \%$ claimed not knowing that allergies were chronic conditions. Patients who dropped out indicated that their reasons for therapy discontinuation were high costs and a lack of perceived efficacy (39\%). This study shows quite bluntly that a lack of education in AIT patients impedes therapy success. ${ }^{22}$ Bender and Oppenheimer ${ }^{5}$ recommend the adaptation of successful management tools used in other chronic diseases, such as effective communication, follow-up, and adequate information. Antico ${ }^{13}$ concentrates on management strategies which focus on provider-, health system-, and patient-related impact factors.

\section{Conclusion}

In conclusion, our investigation revealed a clear peak of dropouts in the first year of AIT. No significant difference was detected between the dropout rates based on the sex of the patients. Also, dropouts could not be allocated to a certain mode of therapy. However, patients who dropped out tended to be younger than the patients in the entire collective. A trusting physician-patient relationship seems to be a crucial component of good adherence to AIT. Our results strengthen this hypothesis. The adherence rates in this individual practice were remarkably better than those reported in other studies, which can be linked to the practice itself, health care delivery, and the practice's emphasis on a positive physician-patient relationship. This study's outcome, however, is limited by its single-center design.

This study provides clear evidence that the first year of therapy is pivotal for patient adherence to AIT. It appears that if patients adhere to their AIT schedule in the first year, they are more likely to complete the rest of their treatment. Our results can, therefore, be interpreted as support for the importance of patient education and for emphasizing the importance of close physician-patient communication during the first year of treatment as decisive factors contributing to the success of AIT.

\section{Acknowledgment}

We thank Gena Kittel for her valuable assistance in editing this manuscript and Dr Neuner for his statistical support.

\section{Disclosure}

The authors report no conflicts of interest in this work.

\section{References}

1. Lee S, Nolte H, Benninger MS. Clinical considerations in the use of sublingual immunotherapy for allergic rhinitis. Am J Rhinol Allergy. 2015;29(2):106-114.

2. Aboshady OA, Elghanam KM. Sublingual immunotherapy in allergic rhinitis: efficacy, safety, adherence and guidelines. Clin Exp Otorhinolaryngol. 2014;7(4):241-249.

3. Canonica GW, Bousquet J, Casale T, et al. Sub-lingual immunotherapy: World Allergy Organization Position Paper 2009. World Allergy Organ J. 2009;2(11):233-281.

4. Canonica GW, Cox L, Pawankar R, et al. Sublingual immunotherapy: World Allergy Organization position paper 2013 update. World Allergy Organ J. 2014;7(1):6.

5. Bender BG, Oppenheimer J. The special challenge of nonadherence with SLIT. J Allergy Clin Immunol Pract. 2014;2(2):152-155.

6. Sieber J, De Geest S, Shah-Hosseini K, Mösges R. Medication persistence with long-term, specific grass-pollen immunotherapy measured by prescription renewals. Curr Med Res Opin. 2011;27(4):855-861. 
7. Kiel MA, Röder E, Gerth van Wijk R, Al MJ, Hop WC, Rutten-van Mölken MP. Real-life compliance and persistence among users of subcutaneous and sublingual allergen immunotherapy. J Allergy Clin Immunol. 2013;132(2):353-360.

8. Egert-Schmidt A, Kolbe JM, Mussler S, Thum-Oltmer S. Patients' compliance with different administration routes for allergen immunotherapy in Germany. Patient Prefer Adherence. 2014;8:1475-1481.

9. Scurati S, Frati F, Passalacqua G, Puccinelli P, Hilaire C, Incorvaia C; Italian Study Group on SLIT Compliance. Adherence issues related to sublingual immunotherapy as perceived by allergists. Patient Prefer Adherence. 2010;4:141-145.

10. Savi E, Peveri S, Senna G, Passalacqua G. Causes of SLIT discontinuation and strategies to improve the adherence: a pragmatic approach. Allergy. 2013;68(9):1193-1195.

11. Senna G, Ridolo E, Calderon M, Lombardi C, Canonica GW, Passalacqua G. Evidence of adherence to allergen-specific immunotherapy. Curr Opin Allergy Clin Immunol. 2009;9(6):544-548.

12. Passalacqua G, Baiardini I, Senna G, Canonica GW. Adherence to pharmacological treatment and specific immunotherapy in allergic rhinitis. Clin Exp Allergy. 2013;43(1):22-28.

13. Antico A. Long-term adherence to sublingual therapy: literature review and suggestions for management strategies based on patients' needs and preferences. Clin Exp Allergy. 2014;44(11):1314-1326.

14. PEI.de [homepage on the Internet]. Langen: Allergene zur sublingualen Immuntherapie, Paul-Ehrlich-Institut, Bundesinstitut für Impfstoffe und biomedizinische Arzneimittel, [updated 2016 September 12; cited 2013 December 12]. Available from: http://www.pei.de/DE/arzneimittel/allergene/therapie-allergene/sublingual/sublinguale-therapie-node. html or http://www.pei.de/EN/medicinal-products/allergens/therapyallergens/sublingual/sublingual-therapy-node.html. Accessed July, 2016.

15. Pfaar O, Bachert C, Bufe A, et al. Guideline on allergen-specific immunotherapy in IgE-mediated allergic diseases - S2k Guideline of the German Society for Allergology and Clinical Immunology (DGAKI), the Society for Pediatric Allergy and Environmental Medicine (GPA), the Medical Association of German Allergologists (AeDA), the Austrian Society for Allergy and Immunology (ÖGAI), the Swiss Society for Allergy and Immunology (SGAI), the German Society of Dermatology (DDG), the German Society of Oto-Rhino-Laryngology, Head and Neck Surgery (DGHNO-KHC), the German Society of Pediatrics and Adolescent Medicine (DGKJ), the Society for Pediatric Pneumology (GPP), the German Respiratory Society (DGP), the German Association of ENT Surgeons (BV-HNO), the Professional Federation of Paediatricians and Youth Doctors (BVKJ), the Federal Association of Pulmonologists (BDP) and the German Dermatologists Association (BVDD). Allergo J Int. 2014;23(8):282-319.
16. Cox L, Larenas-Linnemann D, Lockey RF, Passalacqua G. Speaking the same language: the World Allergy Organization subcutaneous immunotherapy systemic reaction grading system. J Allergy Clin Immunol. 2010;125(3):569-574.

17. Hsu NM, Reisacher WR. A comparison of attrition rates in patients undergoing sublingual immunotherapy vs subcutaneous immunotherapy. Int Forum Allergy Rhinol. 2012;2(4):280-284.

18. Leader BA, Rotella M, Stillman L, DelGaudio JM, Patel ZM, Wise SK. Immunotherapy compliance: comparison of subcutaneous versus sublingual immunotherapy. Int Forum Allergy Rhinol. 2016;6(5):460-464.

19. Pfaar O, van Twuijver E, Boot JD, et al. A randomized DBPC trial to determine the optimal effective and safe dose of a SLIT-birch pollen extract for the treatment of allergic rhinitis: results of a phase II study. Allergy. 2016;71(1):99-107.

20. Leatherman BD, Khalid A, Lee S, et al. Dosing of sublingual immunotherapy for allergic rhinitis: evidence-based review with recommendations. Int Forum Allergy Rhinol. 2015;5(9):773-783.

21. Sondermann N, Shah-Hosseini K, Henkel K, Schwalfenberg A, Mösges R. Erfolgsfaktoren der Adherence bei Hyposensibilisierung [Success factors of adherence in hyposensitization]. Allergologie. 2011; 34(9):441-446. German.

22. Calderon M, Cox L, Casale T, et al. The effect of a new communication template on anticipated willingness to initiate or resume allergen immunotherapy: an internet-based patient survey. Allergy Asthma Clin Immunol. 2015;11(1):17.
Patient Preference and Adherence

\section{Publish your work in this journal}

Patient Preference and Adherence is an international, peer-reviewed, open access journal that focuses on the growing importance of patient preference and adherence throughout the therapeutic continuum. Patient satisfaction, acceptability, quality of life, compliance, persistence and their role in developing new therapeutic modalities and compounds to optimize

\section{Dovepress}

clinical outcomes for existing disease states are major areas of interest for the journal. This journal has been accepted for indexing on PubMed Central. The manuscript management system is completely online and includes a very quick and fair peer-review system, which is all easy to use. Visit http://www. dovepress.com/testimonials.php to read real quotes from published authors. 